\title{
Problem Aspects of E-Governance and E-Learning Management in Bulgaria
}

\begin{abstract}
The world is changing in the 21st century and in the conditions of crisis to function normally it focuses on egovernment. For its part, e-government is the main platform for digital transformation of public institutions, for improving the quality of administrative services, for the transition to rational electronic processes of functioning and management in the public sector and for electronic access to information available to public institutions. This report presents the main points of the development of e-government processes in Bulgaria and the need to combine the process with e-learning. Processes are a challenge that requires us to make new creative and workable decisions in a pandemic.
\end{abstract}

Index Terms - e-government, models, system, administration, development, process.

\section{INTRODUCTION}

In the context of a global pandemic in early 2020, the world is beginning to focus on e-government. For the Bulgarian state, e-government has been a constant priority over the last decade. This is due to the integration into the pan-European policy for the provision of electronic services to EU citizens and the improvement of the business environment are European priorities. The current challenges related to the dynamic digital environment are aimed at full realization of the main state priority for irreversibility of the processes of digital transformation of the administration and public institutions, as well as providing online training for young people in Europe. Providing effective online learning and eprocess management is a way to develop and improve egovernment services for citizens and businesses. Undoubtedly, the synergies and balance between the three directives (innovative technologies, flexible management style and a clear and effective management model). They guarantee the parties make more effective use of the benefits of new technologies and provide citizens with an advantage in terms of for easy access and improvement of existing digital services [1].

Supporting the processes of digitalization and improving the administrative efficiency of the institutions in the Republic of Bulgaria is an important condition for the training of staff by universities. The large-scale introduction of online learning is a new beginning for digital processes, they are a challenge for all of us and in practice we are entering the new time at a fast pace. Improving the accessibility and openness of public institutions for an overall increase in trust in Bulgarian institutions, as well as a new vision for the development of Bulgarian online learning [3]. On the other hand, the e-services projects implemented so far in the country rarely contain a structured analysis and criteria for selection of priority services for citizens, the expected benefits and effects for citizens and businesses. Electronic services are provided very rarely or only in certain cases to meet the needs of the data administration, which makes the investments meaningless. There are no initiatives for the development of priority electronic complex administrative services based on "episodes from life or business" and the transformation of certification services into internal administrative services.

Progress has been made within the European Union in recent years. As many as nine countries (Denmark, Bulgaria, Croatia, Czech Republic, Finland, Slovakia, Hungary, Spain, Italy) adopt specific legislation to promote the implementation of e-government. Also, interoperability between countries as one of their own major achievements in the field of e-government over the last decade [4].

Thus, online learning and e-government are parallel processes that have their challenge to the scientific community and practice. The development of e-government is slow, and the provision of electronic services remains unsatisfactory. The current state of the administration and the level of introduced electronic administrative services for citizens and businesses show that at the end of 2018 the achievements in the introduction of e-government in Bulgaria lag significantly behind the common European framework for development in this area.

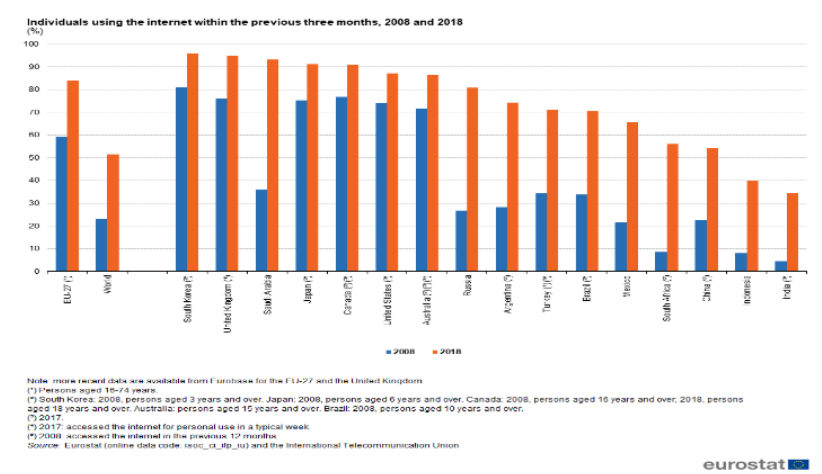

Fig. 1. Individuals using the internet within the previous 2018. Source: Eurostat.

Among them, the creation of new public sector entities responsible for eGovernment policy coordination, monitoring, implementation and support, deployment of eGovernment infrastructure, digital public service delivery 
through eGovernment portals, publication of open data, and investment in digital skills.

\section{OPPORTUNITIES FOR IMPROVING E-GOVERNMENT IN THE Public SECTOR}

In the development of the public sector in Bulgaria in terms of e-government there are corresponding achievements, but also deficits. The results of the implementation of the measures are defined by specific objectives and correspond to the main commitments of the Tallinn Declaration for egovernment, aimed at the implementation of fully digital interaction of citizens and businesses with public administrations.

It is essential for the transformation of the administration and public institutions into digital is the implementation of measures related to ensuring interoperability through the development and subsequent implementation of the concept of interoperability, standards, procedures and technological means for their maintenance, construction, digitization and development of basic registers and their integration [2].

The development of the horizontal and centralized egovernment systems in the Republic of Bulgaria and the application of the unified model for requesting, paying and providing electronic administrative services will provide an opportunity for administrative services to be performed entirely online and implementing the principle of one-time data collection and creation. To facilitate users, the development and management of other channels for access to administrative services through various mobile platforms and devices is provided, which makes them easy to use and accessible at any time from any place. In this regard, the implementation of a single national electronic identification scheme, according to EU Regulation 910/2014, will provide a unified and secure mechanism for identifying individuals when requesting and receiving electronic services, as well as the possibility of cross-border use of electronic services [5].

Given the key role of the eIDAS node in carrying out crossborder electronic identification of citizens of other EU Member States, a measure to ensure its maintenance and development is included. Also included are measures for the development of the Unified Electronic Communications Network (UESM), data centers and the State Hybrid Private Cloud (SSC) - part of the shared resources and key building blocks for providing e-government. The implementation of these policies must find expression in 2023. Thus, these activities and measures must meet the need to continue the process of electronicization of projects and activities launched in the programming period 2014-2020. At the same time, their implementation must lead to the goals set in the Updated Strategy for Development of e-Government. This in turn will outline the new architecture of e-government in Bulgaria and will set a new approach to e-services management. This will contribute to the effective implementation of the commitments of the Republic of Bulgaria according to the strategic documents and current plans, as well as to the political consensus declared in Tallinn for accelerated implementation of the digital agenda of the European Union.
According to the data in the Integrated Information System of the State Administration (IISDA) for 2018, only 194 administrations (33\% of a total of 585 reported administrative structures) provide electronic administrative services. There is a tendency to increase the number of administrations providing administrative services electronically. This process has 4 levels depending on the achieved level of development and the possibilities for electronic services, but for the country the provision of services at level 2 still prevails about $54 \%$ of the total number of provided services [6].

There are still administrations that lack Automated Information Systems (AIS). In the other administrations, some of the implemented ones either do not fully cover all administrative processes or are not in a unified working environment. Some systems are outdated compared to the updated regulatory framework and / or need technological upgrades.

The needs of the administrations overlap, but due to lack of coordination often two or more administrations develop systems similar in technical parameters and functionality, thus duplicating the costs and effort of construction and maintenance. As a result, despite the progress made in the introduction of e-government services in many administrations, the overall benefits for citizens, businesses and the administration itself are not tangible [7]. From the above it should be concluded that there is mistrust among citizens and businesses about the introduction and successful implementation of e-government in Bulgaria, which is clearly shown in the following figure:

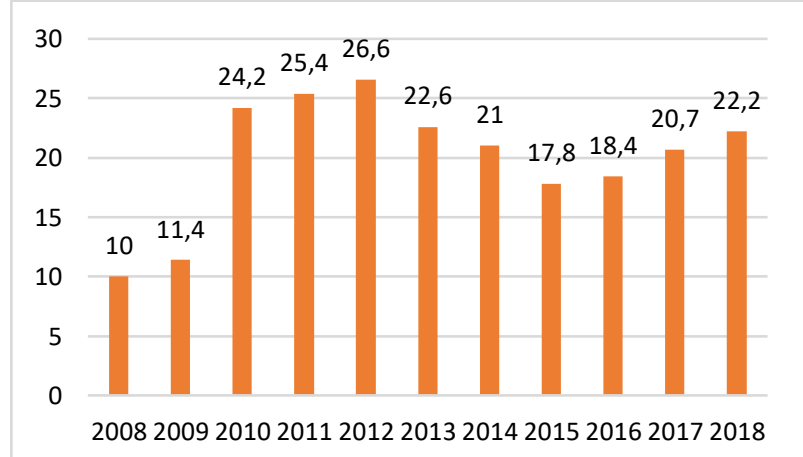

Fig. 2. Use of the Internet by individuals for the purpose of interaction with public institutions (in percentages. Source: NSI.

The introduction, implementation and development of egovernment requires qualified human resources responsible for the development, management, coordination, monitoring, control and audit of ICT programs and projects, achieving interoperability and streamlining administrative processes. Although the topic of e-government policy is openly on the agenda, there are still mixed approaches in the administrative structures regarding the steps of e-government implementation, the maintenance of registers and the possibility for exchange and integration of data between them - a key prerequisite for the implementation of complex administrative services, as well as accurate and correct definition of the roles, rights and obligations of the teams involved in e-government [14]. The tendency is to increase on an annual basis the number of provided administrative services. In this respect, the level of ex officio provision of documents, data or information between administrations, 
public officials or public service providers needed to serve users of administrative services remains low. Citizens and businesses continue to be required to provide information or prove facts and circumstances that are already available to various data controllers, despite existing regulations requiring them to provide them ex officio. The process of removing the requirement from the administrative authorities for certification documents on paper has already started, but the good pace of work from 2017 and 2018 must be continued. These documents need to be gradually replaced by official references in the relevant registers.

\section{FormAtion OF THE TECHNOLOGICAL FRAMEWORK OF E-GOVERNMENT IN BULGARIA}

The development of e-government in Bulgaria is based on the moment of implementation and upgrading of information and communication infrastructures and systems. Modernization of the administrations of the executive and the judiciary with equipment, ICT, development of websites and portals for providing information and services.

The offering and providing electronic administrative services via mobile devices, through which it is possible to request, pay for and provide the services. Training of employees in the administrations in digital skills and ICT [14]. It is important to note that different legislative frameworks have been introduced at national level in the last 10 years level to support and enable public administrations in their modernization efforts. Some were broad e-government activation actions (covering many areas of digital public service delivery and infrastructure deployment), such as Law on e-Government of Bulgaria, or legislation focused on specific aspects of the modernization of the state, as the law introducing mandatory digital communication for business and citizens with public administrations in Denmark.

The main resources in the structure of e-government are divided in the direction of participants in e-government, access channels - multi-channel layer for access to e-services, information layer in which they are grouped, horizontal systems, centralized systems, registers and databases, portal applications, decentralized resources of the administrative bodies and their structures, national centers related to information security, electronic identification centers and other normatively regulated, customer service centers you (call centers).

Also creation of an integration layer, which is responsible for the orchestration between the different levels of interaction and includes an integration bus for exchange of electronic documents, an integration bus for exchange of certifying and reference information, an integration bus for access and management of IT services and data [8].

This means defining a technological layer responsible for the deployment of the technical infrastructure on which all the resources listed above operate and whose duty is to provide a reliable and sustainable environment for the provision of e-government services 24/7.

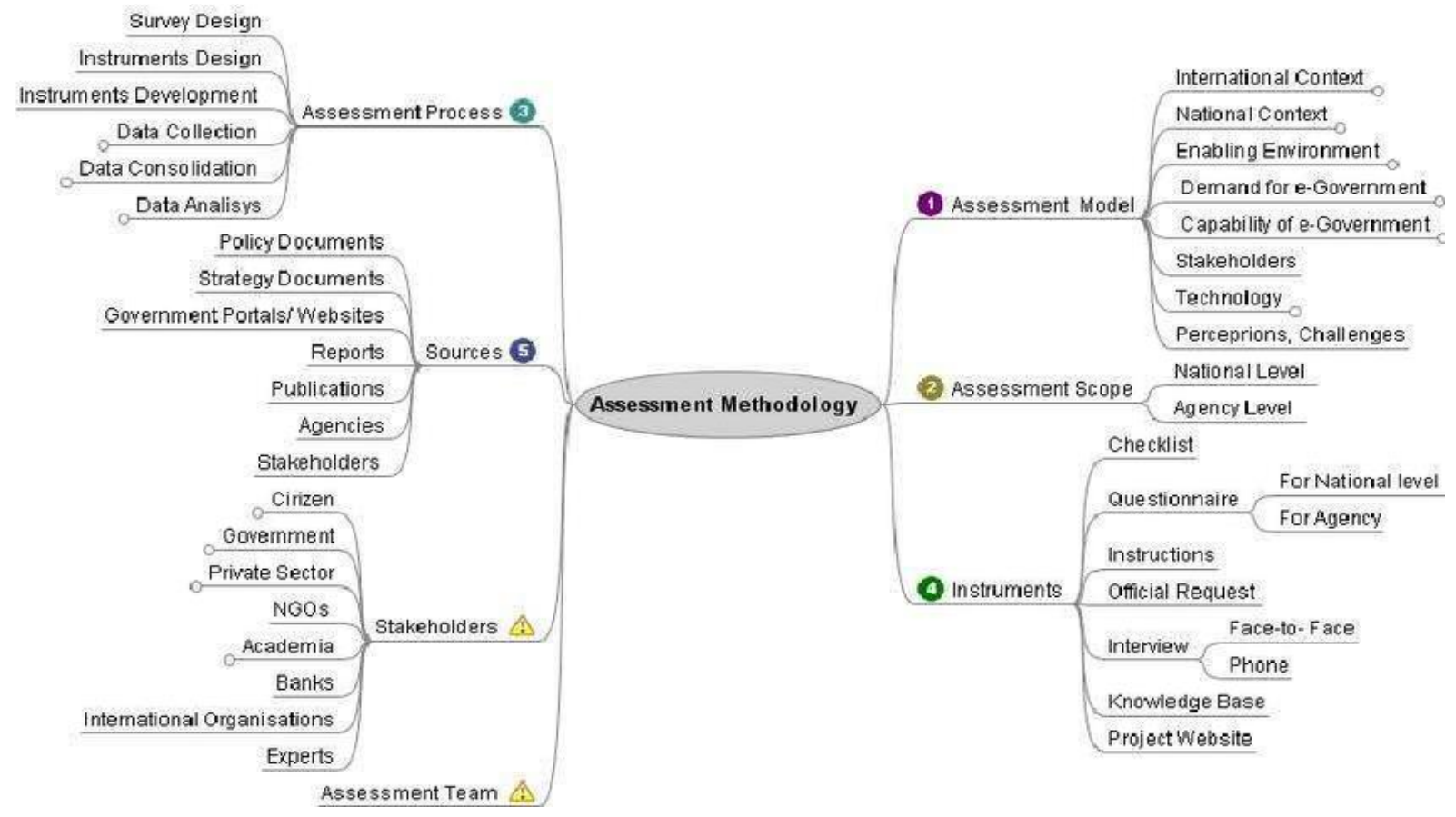

Fig. 3 Basic resources of e-government. Source: https://www.researchgate.net

The unified electronic communications network (UESM) of the administration and for the needs of national security and defense is an integrated network, owned by the state and managed by it with access points in the 28 regional cities and in individual municipalities. This network simultaneously transmits data, voice and video of a certain quality, providing continuous service and real-time service management [8]. The technologies used in EESM allow to virtually unite in a single national information infrastructure the networks of ministries, departments and local administration, preserving their information independence, their autonomous management and excluding any form of unregulated access to the transmitted information. The resources described in the figure will be developed both functionally and technologically. Interoperability covers all layers that affect the provision of e-services. Through the implementation of a 
national electronic identification scheme, the following goals will be achieved to meet the need for centralized electronic identification (e-identification) of individuals in a virtual environment that allows easy and reliable verification of their identity with maximum security [11].

In practice, in countries like Bulgaria, e-government is a serious mechanism to reduce corrupt practices. Its development necessarily includes the deployment of a modern e-government infrastructure. These systems and technologies must be at the heart of the development and delivery of digital public services and the digitalization of public administrations. Building infrastructure seems to be of paramount importance to the European public administration in recent years, with most countries working to make egovernment a national priority for sustainable regional development [7].

It is important to note that electronic passport services must be created in each country. These services for countries like Bulgaria must at the same time have the opportunity to categorize them. For example, readiness to provide open data, for example - policy and use (consisting of presence policy, national coordination, licensing rules and use data). Determining portal maturity (consisting of usability, data reuse, and data dissemination between domains) and open data readiness - impact (consisting of political, social, economic). Another issue that also needs to be highlighted is the number of employees who support the successful implementation of e-government. Their capacity is limited, with usually one or two employees in most administrative structures responsible for e-government and even being assigned responsibilities and other activities such as managing human resources, accounting and finance, information technology and others [9]. The administration has not implemented a comprehensive system of planning of human resources, both in terms of the required number, and in terms of competencies that relevant experts should have to guarantee the desired effectiveness and efficiency of administration in general and in the implementation of the objectives set. In Bulgaria there is not an adequate link established between the necessary knowledge and skills in the administration and the regulated admission in different studies in the universities. This leads to a large number of tertiary graduates who cannot find good professional realization, and a shortage of qualified experts in other areas. This trend is confirmed by the increased number of competitions in the state administration, suspended due to lack of candidates meeting the minimum set of requirements for the respective job position. On the other hand, there is an increase of the number of competitions completed without ranking as neither of the candidates have performed well. In total, about $15 \%$ of the announced competition procedures completed without appointment on the above grounds. Close contacts are not established between the administration and the higher education institutions where professors from leading universities in the country encourage the most promising students to seek their career in the public sector.
TABLE I: DEGREE OF PROVIDING E-SERVICES IN THE 10 LARGEST MUNICIPALITIES IN BULGARIA

\begin{tabular}{ccccc}
\hline \multirow{2}{*}{ Municipalities } & \multicolumn{4}{c}{ Data by years } \\
\cline { 2 - 5 } & 2012 & 2014 & 2016 & 2018 \\
\hline Sofia & 1,00 & 4,00 & 6,00 & 6,80 \\
Plovdiv & 1,78 & 2,94 & 3,75 & 5,20 \\
Varna & 3,00 & 4,11 & 5,01 & 5,78 \\
Burgas & 2,12 & 2,29 & 3,13 & 4,13 \\
Stara Zagora & 2.48 & 2,78 & 3,45 & 4.34 \\
Pleven & 1,78 & 2.62 & 3.12 & 4.08 \\
Ruse & 1,12 & 1,45 & 2.40 & 3,05 \\
Pazardjik & 2,57 & 2,46 & 3,30 & 3,76 \\
Haskovo & 1,48 & 2,81 & 2.98 & 3,84 \\
Yambol & 3,13 & 4,23 & 4,46 & 4,78 \\
Country & 1,75 & 2,07 & 2,86 & 3,34 \\
\hline
\end{tabular}

Source: Reports of the municipal administrations, calculations of the author

As we can see, in the leading municipalities in Bulgaria they start from a lower level. It is assumed that those who are at level 1 do not have electronic services, according to their annual reports. Although for the period 2012-2018 their number has increased the number of municipalities offering electronic has increased can still be much desired in this situation [9].

\section{Structuring AND NeED FOR E-LEARNING AND ITS ROLE}

Conducting trainings for competence development of employees is an integral part of their professional development. In recent years, however, specific resources for training have not been provided for allocation to the respective administrations. Due to this fact in most cases they can not involve their employees in the required courses. Elearning is knowledge driven by electronic media. According to the glossary of e-learning terms, the meaning is as follows: education via the Internet, network or computer. The network allows data transfer, and through them skills and knowledge are built. E-learning refers to the e-learning process and includes web-based learning, computer-based learning, virtual classroom articles and digital collaboration [10]. The essence of e-learning goes through the Internet, intranet / extranet, audio or video devices, satellite TV and CD-ROM. The e-learning is presented in a very interesting way in the book "701 E-learning Tips" by Masie Center. There are types of e-learning sent by managers and training professionals from around the world. The term "e-learning" is not synonymous with the term "distance learning" [13].

It also refers to the description of traditional forms of learning that use elements of digitalization in the daily learning process. These so-called "hybrid courses" are currently much more than remotely offered. For example, in the United States, $70 \%$ are distance learning courses and $80 \%$ are hybrid courses. E-learning is usually associated with the targeted use of information and communication technologies in teaching and learning. Thus, the aim of the European Union is to guide learners or assist them in specific tasks. The basis of e-learning are the so-called "Course Management Systems", also known as "Learning Management System" or LMS (Learning Management Systems) and "Virtual Learning Environment" or VLEs (Virtual Learning Environments). These are systems for multimodule electronic presentation of lecture materials for students. In this way, they can "connect" with their teachers by submitting written assignments 
electronically, participating in interactive educational sessions or taking an exam in real time. In such an environment, teachers can with minimal effort and resources communicate individually or simultaneously with students, which helps them more easily evaluate their work [2]. The students themselves are made as easy as possible when working in a team. They find Course Management Systems as the main portal for access to other services and resources that can meet some of their information needs. The growing interest in e-learning seems to come from several areas. These include organizations that traditionally offer distance learning programs. For them, the application of e-learning is a logical continuation of their activities using distance learning. The corporate sector, on the other hand, is interested in e-learning as a way to reduce the cost of employee training. Educational organizations are also interested in e-learning. They adopt elearning as a way to improve access to their curricula. The development of e-learning is directly related to the growing opportunities and the reduction of the price for access to information and communication technologies. The ability of information and communication technologies to support learning and teaching based on the use of multimedia resources is also the reason for the growing interest in elearning. Despite the great interest in e-learning, it does not have unlimited possibilities. A significant obstacle to the development of e-learning is the lack of access to the necessary technological infrastructure, without which elearning cannot exist [11]. Poor technological infrastructure can do more harm than good to teachers and learners. Software and hardware prices are falling, but there are often other costs that are often overlooked, such as infrastructure maintenance and teacher training costs.

Many online colleges and schools make heavy use of mastery learning. The concept has been around for a while, but it gained popularity in online education thanks to Khan Academy. Mastery learning requires students to master a concept or skill before moving ahead. Instead of treating a 60 or 70 as a "passing grade," students are expected to demonstrate mastery in that topic by answering all questions correctly.This standard sounds hard, but it makes good sense if you think about it. We wouldn't settle for a cardiologist who is only ninety percent competent to perform heart surgery; or a dentist who cleans only seventy percent of your teeth. Likewise, mastery learning requires students to master the material with demonstrable one hundred percent competency[12]. For Khan academy students, mastery is measured as ten correct answers in a row, with the questions drawn from a battery of subject-specific questions. If your school utilizes mastery learning, then expect a lot of retesting. You'll also want to make heavy use of online tutorials and any teacher assistance available to you. You can't coast on a score of 70 and keep flowing through your degree program. You'll need to fully grasp the material or else your college experience will be slow and painstaking.

Online colleges can be surprisingly adept at project-based learning (PBL). Many conventional classrooms have long operated on a project-based model, where instead of reading chapters, answering questions, and taking tests, students work on subject-specific educational projects such as building a greenhouse, designing a website, or debating the specifics of the French Revolution — possibly in era-accurate garb.
Online colleges, of course, must operate a little differently, since you can't exactly build a literal greenhouse entirely online. You can, however, construct 3D models of buildings, design web pages, write short stories, and solve puzzles. Projects are often group work but they aren' to be. Welldesigned PBL programs cover all the main learning outcomes expected for a given subject area while also training students to share and organize responsibilities, give peer review, work in teams, engage in self-directed learning, break down projects into discrete and manageable parts, and solve complex problems. It's important that, as an online student, you remain plugged into the process. You will need to learn how to communicate, cooperate, and be a good team player. A great deal of your success in a PBL setting depends on your ability to work with other students through the online medium.

For many online students, isolation can be a serious challenge. They may drift collectively through their studies as strangers who never truly engage one another. Fortunately, schools and teachers are increasingly keen to this concern. A growing effort implements collaborative online learning strategies to confront this challenge [13].

Collaborative learning — sometimes known as "learning communities" or "cooperative learning" — refers to the commonsense notion that we often learn best by working with others as a group. Collaborative learning applies a deliberate goal-oriented focus to these exercises so students are not just working together on an activity, but are also actively learning from each other, through each other, and about each other, all while completing assignments together. In online education, collaborative learning is powered by a wide range of social media technologies including videoconferencing, texting, email, teleconferencing, and workflow programs such as Trello and Slack. Each of these applications has helped to make the world a smaller place for students, making global collaboration a real possibility. Collaborative learning is an increasingly popular option in today's online classrooms. As an online student, don't be surprised if you are called upon to collaborate with classmates on assignments. You would do well to learn how to use some collaborative platforms. In addition to Trello and Slack, commonly used applications include ClearSlide, GoogleDocs, and Skype. Chances are you'll also eventually use one or all of these applications in your professional life as well.

\section{CONCLUSION}

With regard to e-government, it can be said that the country is making slow progress. In our conditions there is a single portal for electronic administrative services (https://egov.bg), Portal for open data of the Republic of Bulgaria (http://opendata.government.bg/), respectively an Integrated information system of the state administration has been implemented, ensuring publicity, monitoring, greater accountability and control over the organization and activities of the administration to achieve efficiency and effectiveness in its work. A Unified model for the provision of electronic administrative services through the use of horizontal egovernment systems has been created. Bulgaria is ahead of the EU average of $59 \%$ in the use of "open data" and reaches $76 \%$. The process of optimization of resources and processes 
and implementation of the principle "the user in the center of the administrative service" is progressing. This must lead to transnational interoperability and "cross-border e-public services" for the development of society and business within the single market.

Also to change the organizational culture of the administration and public institutions. With regard to the improvement of e-government, it is necessary to increase the qualification and digital competencies of those employed in the public sector. Also turning the administration into a partner of citizens and businesses and increasing public trust in institutions, which is a prerequisite for improving the quality of the democratic process. At the same time, promoting economic growth and improving socio-economic indicators by improving the business environment and creating opportunities to improve the quality of the workforce. As well as optimization of the processes related to public expenditures due to the introduction of e-government and more efficient use of public resources, including its redirection to the implementation of other state priorities.

Online education has radically changed the landscape of modern education. We're learning in a new and more fluid environment, one ripe with opportunities for students of every kind. These emergent approaches to content and curriculum are part of a whole new wave of learning opportunities distinguished by web mediation. As these trends demonstrate, online education is producing a whole new set of strategies for improving engagement, retention, and mastery.

\section{REFERENCES}

[1] Bellman, B. and Rausch, F., Enterprise Architecture for e-Government, Electronic Government 2004, Lecture Notes in Computer Science, Volume 3183/2004. Springer Berlin / Heidelberg New York (2004) 4856.

[2] Boneva, M. News in management information systems. In: Scientific Papers of the University of Ruse - 2012, Volume 51, Series 5.1, Ruse, Publishing Center at the University of Ruse, 2012, pp. 95-103, ISBN 1311-3321.

[3] Gankova-Ivanova, Zwetelina, Verwaltungskapazität, Verwaltungsmodern-isierung und E-Government in Bulgarien, Primat des Handelns. Festschrift für Walter Maier, Richard Boorberg Verlag, Stuttgart, 2012, S.204-221.

[4] Georgieva, M, V. Petrov, 2018 E-governance- improving employment through smes and addressing the challenges for sustainable regional development in Dobrich province.

[5] Mihaleva, S. The concept of "e-government" in the context of electronic control ttps://ejournal.vfu. bg/en/pdfs/ Svetla_MihalevaKoncepciata_'Elektronno_pravitelstvo'_v_kontektsta _na_elektronnoto_upravlenie.pdf.

[6] Milev, P., Trends in the Development of Architecture Solutions for Web Publishing Systems, Business Management, Issue 2, pp 16-30, 2019.

[7] Marinov, O., Tsankova, R. (2015). Impact of ICT on administrative management processes. VII International scientific conference "eGovernance". Conference proceedings. Sozopol, Bulgaria.

[8] Naydenov, Kl. (2017), Regional differences and trends in egovernance, IX-th International Scientific Conference "E-Governance and ECommunications", June, 2017, Sozopol, Bulgaria, p. 45 - 52.

[9] National Statistical Institute (NSI) Key Indicators for Bulgaria, 2019.

[10] Roadmap for implementation of the Strategy for development of egovernment in the Republic of Bulgaria for the period 2016-2020.

[11] Spasov, K. Problems of the development of the e-government system in Bulgaria, presentation of the conference "Administrative reform through e-government" 2014.

[12] Savoldelli, A., Codagnone, C., \& Misuraca, G. (2014). Understanding the e-government paradox: Learning from literature and practice on barriers to adoption. Government Information Quarterly, 31, S63-S71.
[13] Tsankova R., Georgieva, S. (2012). On opportunities for standardization in the administrative-management processes. IV International scientific conference "e-Governance"[Bul]. Conference proceedings. Sozopol. Bulgaria.

[14] Tolbert, C. and Mossberger, K. The effects of e-government on trust and confidence in government. In Proceedings of the 2003 Annual National Conference on Digital Government Research (Boston, MA, May 18--21, 2003). ACM International Conference Proceeding Series, vol. 130. Digital Government Research Center, 1-7.

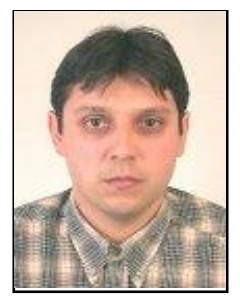

Associate Professor Kamen Petrov is a lecturer at the University of National and World Economy in Sofia, Bulgaria. His publications are in the field of administration and management. He specializes in the field of regional development and territorial management. He has more than 50 publications and 4 monographs on regional development and geoeconomics. Deputy Dean of the Faculty of Management and Administration. 